\title{
Registro de trabajos de investigación sobre tuberculosis y COVID-19 en PRISA o REPEC
}

\section{Registry of research studies on tuberculosis and COVID-19 in PRISA or REPEC}

\author{
Joel Christian Roque-Henriquez ${ }^{1,2, a}$, Duilio Fuentes-Delgado ${ }^{1, b}$, Yolanda Angulo-Bazán ${ }^{1, c}$
}

$\mathrm{DOI}$

https://doi.org/10.35434/rcmhnaaa.2021.14Sup1.1189

\section{Señor editor:}

Uno de los elementos que garantiza el desarrollo de investigaciones éticas es el registro de estas ideas en repositorios o bases de datos que permitan que la comunidad científica conozca qué trabajos se encuentran en curso; así como, visibilizar los vacíos en el conocimiento y detectar posibles sesgos de información, debido a las diferencias entre lo planificado en el protocolo de investigación y lo que finalmente es publicado $^{(1)}$. En ese sentido, la declaración de Helsinki, desde su modificación en el año 2013, recomienda que toda investigación que involucre seres humanos debería estar registrada en una base de datos accesible antes del reclutamiento del primer participante ${ }^{(2)}$. Por ello, el ordenamiento institucional y la promoción del registro de las ideas de investigación, independientemente de la fase en la que se encuentren, es indispensable en un país como Perú, que aún adolece de la falta de un Sistema Nacional de Bioética o de Integridad Científica.

En diciembre de 2014 se aprueba la Ley de Prevención y Control de la Tuberculosis en el Perú (Ley N³0287), la cual en su artículo 39 establece que el Instituto Nacional de Salud (INS) debe implementar un registro de investigaciones científicas referentes a tuberculosis ${ }^{(3)}$. En mayo de 2016 se aprueba el Reglamento de la Ley $N^{\circ} 30287$ (DS N ${ }^{\circ}$ 021-2016-SA) que en su artículo 42 inciso 42.3 establece que el "El registro de investigaciones observacionales y experimentales en tuberculosis es obligatorio y público. Será difundido a través de la página web del INS”(4).

En el marco de lo señalado, el INS ya contaba con el Registro Peruano de Ensayos Clínicos (REPEC, https://ensayosclinicos-repec.ins.gob.pe/) ${ }^{(5)}$ en la cual se deben registrar los ensayos clínicos que se rigen por el Reglamento de Ensayos Clínicos (DS N ${ }^{\circ}$ 021-2017-SA)(6), y desarrolla la plataforma de Proyectos de Investigación en Salud (PRISA, https://prisa.ins.gob.pe/) $)^{(7)}$ para el resto de ensayos clínicos u otros diseños de investigación.

Posteriormente en abril de 2020, en el marco de la pandemia ocasionada por el virus SARS-CoV-2 responsable de la enfermedad COVID-19, el Estado peruano mediante DS $N^{\circ} 014-2020-S A$ establece la obligatoriedad del registro de las investigaciones científicas de la enfermedad COVID-19 en la plataforma PRISA y REPEC, según corresponda $^{(8)}$.

Teniendo como población de estudio a los artículos originales u originales breves, se realizó dos búsquedas sistemáticas en MEDLINE al cual se accedió a través de PubMed (https://pubmed.ncbi.nlm.nih.gov/), una para tuberculosis (TB) [(tubercul* OR scrofula* OR mantoux OR "pott's disease") AND Peru Filters: from 2017/1/1 - 2021/6/8 Sort by: Publication Date] y otra para COVID-19 [(COVID-19 OR SARS-CoV-2 OR 2019nCoV OR "2019 novel coronavirus" OR "Coronavirus disease 2019") AND Peru Filters: from 1000/1/1 - 2021/6/8 Sort by: Publication Date].

En TB se identificaron 246 artículos, solo $16(6,5 \%)$ estuvieron registrados, once en PRISA y cinco en REPEC. Con relación a COVID-19 se recuperaron 264 artículos,

\author{
FILIACIÓN \\ 1. Instituto Nacional de Salud, Lima, Perú. \\ 2. Universidad de San Martín de Porres, Lima, \\ a. Médico Cirujano, Magister en \\ Epidemiología Clínica. \\ b. Médico Internista, Magister en Bioética \\ c. Médico Cirujano, Candidato a Magister en \\ Epidemiología Clínica. \\ ORCID \\ 1. Joel Christian Roque-Henriquez \\ 0000-0002-9206-2422 \\ 2. Duilio Fuentes Delgado \\ 0000-0002-0086-2546 \\ \begin{tabular}{l} 
Yolanda Angulo-Bazan \\
$0000-0002-7280-170 X$ \\
\hline
\end{tabular} \\ CORRESPONDENCIA \\ Yolanda Angulo Bazán \\ Dirección: Av. Defensores del Morro 2268 (Ex \\ Huaylas) Chorrillos. \\ EMAIL \\ yangulo@ins.gob.pe
}

CONFLICTOS DE INTERÉS Ambos autores laboran en la Oficina Ejecutiva
de Investigación de la Oficina General de Investigación y Transferencia Tecnológica del Instituto Nacional de Salud.

CONTRIBUCIONES DEAUTORÍA

Todos los autores participaron en la concepción, recolección de información, redacción y aprobación de la versión final del artículo.

FINANCIAMIENTO

Instituto Nacional de Salud.

REVISIÓN DE PARES

Recibido: $14 / 06 / 2021$

Aceptado: 08/09/2021

\section{COMO CITAR}

Roque-Henriquez, J., Fuentes-Delgado, D., \& Angulo-Bazán, Y. Registro de trabajos de investigación sobre tuberculosis y COVID-19 en PRISA o REPEC. Revista Del Cuerpo Médico Hospital Nacional Almanzor Aguinaga Asenjo, 2021,14 ( S u p 1 ), 98 - 99 . https://doi.org/10.35434/rcmhnaaa.2021.14S up1.1189

Esta obra está bajo una Licencia Creative Commons Atribución 4.0 Internacional. Versión Impresa: ISSN: 2225-5109 Versión Electrónica: ISSN: 2227-4731 Cross Ref. DOI: 10.35434/rcmhnaaa OJS: https://cmhnaaa.org.pe/ojs 
únicamente $26(9,8 \%)$ estuvieron registrados, 24 en PRISA y dos en REPEC (Figura 1).

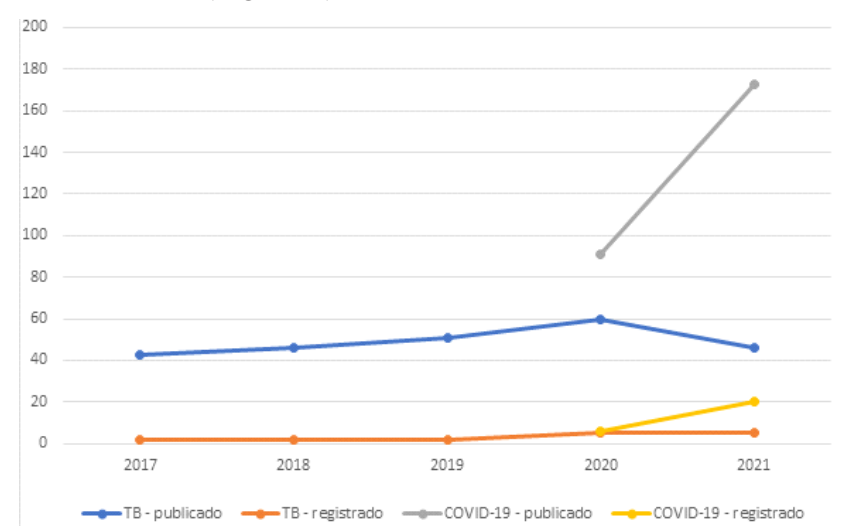

*El registro se encuentra actualizado hasta el 31 de julio del 2021

Figura 1.

Registro en PRISA o REPEC de los trabajos de investigación publicados en MEDLINE (2017-2021).

Todos los ensayos clínicos publicados sobre TB y COVID-19 que se rigen por el Reglamento de Ensayos Clínicos estuvieron registrados en REPEC; sin embargo, hay un incumplimiento por parte de los investigadores en el registro de sus trabajos en PRISA. A fin de mejorar esta problemática, es fundamental: i) aumentar los mecanismos de promoción de la plataforma PRISA, ii) generar incentivos para el registro de los proyectos de investigación, iii) mejorar el diseño, versatilidad, campos de información solicitados y precisión del reporte estadístico brindado por PRISA, iii) que las instituciones clave dentro de la gestión de los proyectos de investigación como unidades de investigación, instituciones que financian proyectos de investigación, comités de ética en investigación, revistas científicas, entre otros, implementen dentro de sus procesos mecanismos para que los investigadores cumplan con registrar sus trabajos. Cabe precisar que PRISA no impide el registro de investigaciones concluidas, previas a la emisión de la norma, y que solo un artículo sobre COVID-19 se publicó en una fecha anterior.

Es así como, ante lo descrito previamente, se requiere reforzar y reiterar a la comunidad científica, que independientemente de la obligación legal que se tiene en Perú de registrar estudios en algunas áreas del conocimiento; es muestra de transparencia e integridad hacia los lectores y ellos mismos, mostrar el proceso de la investigación y los cambios que pudiera haber, desde la concepción, planificación y ejecución, hasta la publicación.

\section{REFERENCIAS BIBLIOGRÁFICAS}

1. Loder E, Groves T, MacAuley D. Registration of observational studies. BMJ. 2010;340:c950. doi:10.1136/bmj.c950.

2. World Medical Association. Declaration of Helsinki: Ethical Principles for Medical Research Involving Human Subjects. JAMA. 2013;310(20):2191-4. doi:10.1001/jama.2013.281053.

3. Congreso de la República (Perú). Ley N 30287, Ley de Prevención y Control de la Tuberculosis en el Perú. [Internet]. Lima: MINSA; 2014 [ c it ado 21 abr de 2021 ]. Disponible en: https://www.gob.pe/institucion/minsa/normas-legales/29699130287.

4. Ministerio de Salud. Aprueban el Reglamento de la Ley $N^{\circ} 30287$, Ley de Prevención y Control de la Tuberculosis en el Perú (Decreto Supremo N 021-2016-S.A.) [Internet]. 2016 [citado 21 abr de 2021]. Disponible en: http://web.ins.gob.pe/es/node/3263.

5. Instituto Nacional de Salud. Registro Peruano de Ensayos Clínicos (REPEC) [Internet]. [citado $21 \mathrm{abr}$ de 2021]. Disponible en: https://ensayosclinicos-repec.ins.gob.pe/.

6. Instituto Nacional de Salud. Registro Peruano de Ensayos Clínicos Normatividad Vigente [Internet]. [citado $21 \mathrm{abr}$ de 2021]. Disponible e n : $\quad$ h t t ps: / / e n s a y o c l i n i cos repec.ins.gob.pe/regulacion/normatividad-vigente.

7. Instituto Nacional de Salud. Proyectos de Investigación en Salud (PRISA) - Inicio [Internet]. [citado 21 abr de 2021]. Disponible en: https://prisa.ins.gob.pe/.

8. Ministerio de Salud. Establecen medidas para asegurar el adecuado desarrollo de los ensayos clínicos de la enfermedad COVID-19 en el país-Decreto Supremo N ${ }^{\circ}$ 014-2020-SA [Internet]. Lima: El Peruano; 2020 [citado 21 abr de 2021]. Disponible en: http: / / busquedas.elperuano.pe/normaslegales/establecenmedidas-para-asegurar-el-adecuado-desarrollo-de-l-decretosupremo-n-014-2020-sa-1865491-9/. 